\title{
Seventeenth-Century Solar Observations: Fundamental Results with Amateur Instruments
}

\author{
E. Ribes-Nesme, J.C. Ribes
}

Observatoire de Paris, Section d'Astrophysique,

5, place Jules-Janssen, F-92195 Meudon Principal Cedex, France

\begin{abstract}
The equipment used by professional astronomers in past centuries was no better than that used by modern amateurs. Systematic observation of the Sun began in the 17th century and continuity of observations is very important for understanding the solar cycle.

Results obtained from historical observations were presented, in particular covering the Maunder Minimum.

Continued systematic observation is important for the understanding of longterm solar-terrestrial relations.
\end{abstract}

\section{References}

Ribes, E., Ribes, J.C., Barthelot, R.: "Solar diameter and solar rotation during the Maunder minimum" in Proceedings of Helio-asteroseismology, Aarhus meeting, Christensen \& Dalsgaard (eds.), 1986

Ribes, E., Ribes, J.C., Barthelot, R.: Nature, 326, (No.6108), 52-5, 1987

Ribes, E., Ribes, J.C., Barthelot, R.: "The solar envelope has expanded during the Maunder minimum: by how much?", in Proceedings of Vancouver meeting, I.G.G.A., August 1987, in press

Ribes, E., Ribes, J.C., Barthelot, R.: "On the accuracy of Picard and La Hire's observations of the Sun and Jupiter during the seventeenth century", Nature, in press, 1988 